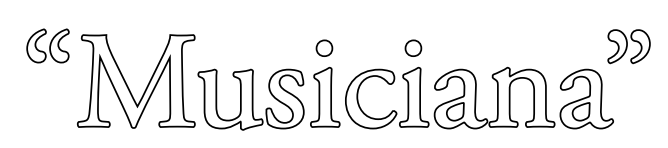

\title{
la semilla de una emisora cultural ${ }^{*}$
}

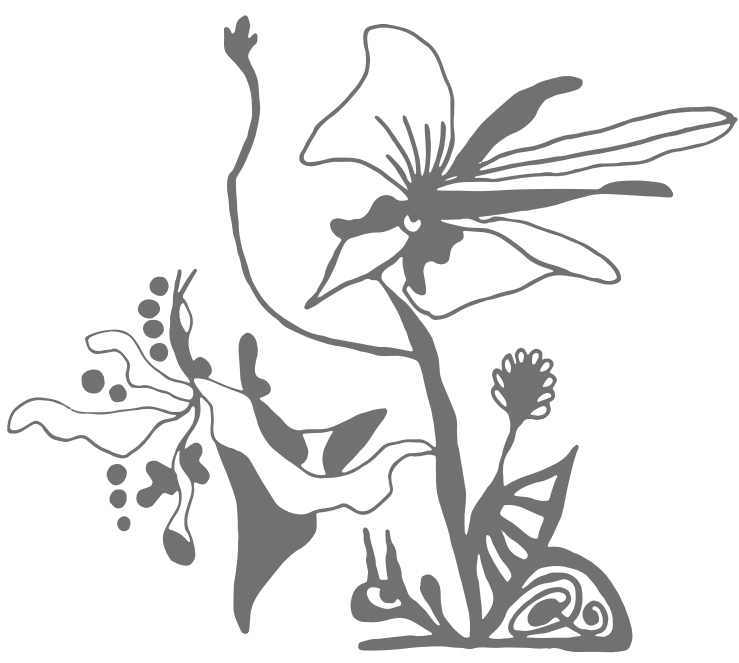

Me siento muy honrada de acudir a esta noble y casi cincuentenaria Casa de estudios cuyo rector y Consejo Universitario han tenido la gentileza de nombrarme Profesora Honoraria, distinción que me abruma, pero que llevaré orgullosa, tratando siempre de desplegar mis mejores esfuerzos para estar a la altura de tal merecimiento.

Asimismo, agradezco las palabras tan estimulantes de mi amigo, el poeta Manuel Pantigoso, que las atesoro en toda su intención.

\section{La música en la vida humana}

Como lo mío es la música quisiera comenzar esta disertación refiriéndome a ella, en tanto alimento espiritual básico para el desenvolvimiento de la vida humana. Comenzaré diciendo que toda vida es sonido. Siempre estamos rodeados de sonidos: la naturaleza canta, y canta el hombre desde que apareció sobre la Tierra. Nuestro oído, maravillosamente construido, capta tonos y ruidos, todo un mundo de sonidos que, sin embargo, no son sino una mínima parte de la inconcebible multitud de sonoridades que alberga el Universo.

\footnotetext{
* Discurso ofrecido el 17 de julio del 2013 con motivo de la distinción como Profesora Honoraria de la Universidad Ricardo Palma.
}

"La música es el palpitar de la vida eterna"

Romain Rolland
La naturaleza está, pues, llena de sonidos, llena de música, siempre lo estuvo. Han pasado muchos millones de años antes de existir un oído humano para escucharla. El armonioso cantar de los pájaros, el suave murmullo del agua, el gemido del vendaval, del trueno, o el horrendo estallar de un volcán. Y todo esto no es más que una pequeña parte de los sonidos existentes en la naturaleza.

Enorme e impresionante ha sido la influencia del sonido de la música en el alma del ser humano. De ahí sus múltiples aplicaciones legendarias o actuales, de ahí su importante papel en la cultura, en la religión, en acciones colectivas (fiestas, revoluciones, guerras) y en sus aplicaciones modernas como en la medicina, en la psicologíay en la industria.

El efecto de la música obra tanto sobre el individuo como sobre la masa. La hallamos, por ejemplo, enlas revoluciones o en las guerras: pensemos tan solo en la fuerza arrebatadora de "La Marsellesa" en Francia.La música es, en la mano del hombre, como una varita mágica: su hechizo puede comprender desde el despertar de los sentimientos más nobles hasta el desencadenamiento de los instintos más viles; desde la unción profunda hasta la embriaguez y la inconsciencia cercanas a la locura; desde la pureza más elevada hasta el sensualismo más brutal.

Las variedades en el campo de la música son infinitas. ¡Una gran distancia existe entre una primitiva melodía de tres notas eternamente repetidas y la sinfonía de un gran maestro; entre las danzas rituales de Oriente y el arte lírico europeo; entre el canto gregoriano y el jazz! Y, 
sin embargo, todo esto vive simultáneamente, ahora mismo, en nuestro mundo. Y para todo ello empleamos la misma palabra: Música.

La definición de la música es múltiple: es un fenómeno acústico para los prosaicos; un problema técnico de melodía, armonía, contrapunto y ritmo para los profesionales; una expresión del espíritu que nos puede elevar al infinito y cuya trascendencia encierra todos los sentimientos humanos ligados a los principios y valores de la humanidad, para los que verdaderamente la aman de todo corazón.

\section{La experiencia de la difusión musical a partir de "Musiciana"}

Permítanme ahora compartir con ustedes algunos recuerdos que se fueron hilvanando a lo largo de mi vida, desde los primeros años, hasta conformar una especie de marco referencial de mi propia existencia.

Tenía cuatro años cuando mi padre compró un piano, que conservo hasta hoy, el cual nos introdujo a mis hermanas y a mí en la música clásica. Fue un descubrimiento maravilloso que no solo ocupó mi vida desde muy niña sino que me permitió conocer otros instrumentos como la melódica y el acordeón, que me depararon muchos buenos momentos $y$, además,me impulsaron a estudiar y aprepararme con el fin de presentarme exitosamenteen diversos Concursos Nacionales.Hasta los veintiún años dediqué mucho tiempo al estudio de ambos instrumentos y formé parte de conjuntos de acordeonistas. Además, integré diversos grupos corales con los cuales viajé dentro y fuera del país.

Sin embargo, siempre me inquietó la poca o ninguna información disponible en Lima acerca de los compositores clásicos y de sus obras. Esta deficiencia me llevó a idear un programa que me permitiera no solo transmitir música sino también hablar de ella, de los compositores, de los estilos, de las orquestas yde los intérpretes. Así, nació el proyecto "Musiciana” que concebí como un programa radial, y con él bajo el brazo me presenté un día a Radio Selecta, la única emisora peruana que transmitía la llamada "música clásica".

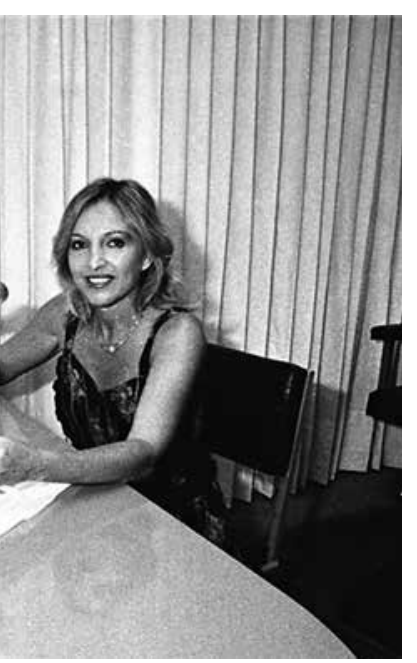

Eso fue en 1973, hace cuarenta años. Desde ese año, "Musiciana" se paseó por otras emisoras que me brindaron un espacio para proseguir con mi cruzada de difundir la música y de educar a través de ella.

Quiero apuntar como anécdota que, además de Radio Selecta, en los años cincuenta y sesenta, las emisoras peruanas respetaban las fiestas religiosas y transmitían música clásica. Asimismo, en los periódicos de la época podíamos leer con avidez qué obras se transmitían en Radio Nacional, Radio El Sol o Radio Panamericana, por citar algunas, desde el Jueves Santo hasta el Domingo de Pascua o de Resurrección.

Volviendo a la idea de crear un programa que impulsase la educación musical, viene a mi memoria la representación de "Carmina Burana", maravillosa composición de Carl Orff, para lo cual la empresa organizadora había contratado, con no poco esfuerzo, a un contratenor argentino. El contratenor es el cantante adulto que canta en falsete como si fuera mezzosoprano, detalle éste del que no se tenía información adecuada. Su actuación dio lugar a que el público reaccionara burlonamente. Yo me encontraba en el coro, parte importante de la obra, y escuché asombrada las risas y los comentarios adversos. Me pregunté entonces: “¿No hubiera sido mejor que el público recibiera previamente la información adecuada y así se hubiese evitado este "bache cultural"?" Pero éste fue solo un evento. Luego, vinieron otros, y uno de ellos desencadenó la prevista reacción manifestada en un programa radial dedicado a informar a los asistentes a los conciertos, a los estudiantes de los colegios y al público en general, acerca de variados e importantes detalles del mundo de la Música.

"Musiciana" se convirtió de esta manera en el espacio musical, único en su género, que se transmitió durante diez años en cuatro emisoras: Radio Selecta -que pronto cerró sus puertas-, Radió Unión, Radio Miraflores y Radio del Pacífico. La falta de seguridad para seguir transmitiendo mi programa hizo que, hacia fines de 1983, juntoa mi esposo Álvaro Llona y a un selecto grupo de amigos, decidiéramos formar una Asociación Cultural que tuviera su propia frecuencia. Así fue como nació la Asociación Cultural Filarmonía, 
entidad sin fines de lucro, con el objetivo principal pedagógico y didáctico de"dedicarse al desarrollo y difusión de la música clásica, selecta y erudita, así como otras manifestaciones culturales con el fin de procurar el mejoramiento del nivel educativo de la población”.

Sin embargo, fue el destino el que nos colocó al lado del doctor Alejandro Miro Quesada Garland -ilustre periodista y gran impulsor de la cultura- quien de inmediato valoró la importancia del proyecto de crear una radio cultural, celebrando con la Asociación el convenio que hizo realidad, el 1 de enero de 1984, el sueño de poner al aire "Sol Armonía", en los 88.9 de la Frecuencia Modulada, con diecisiete horas diarias de programación de música selecta.

Han transcurrido casi treinta años desde entonces y el camino recorrido por la única emisora cultural del Perú ha sido laborioso, a veces penoso pero lleno de satisfacciones, pues no hay mayor complacencia que saber que lo que uno hace no solo gusta sino culturiza y abre al hombre las puertas del desarrollo espiritual, que es la base para alcanzar el progreso total del hombre y de la sociedad.

En la nueva emisora cultural, el programa "Musiciana" siguió transmitiéndose a las 8:00 de la mañana, siempre con las mismas características: presentar una obra con un comentario sobre ella, incluyendo al compositor y a los intérpretes. Pero junto a esta recordada "Musiciana" se fue armando toda una red de programas con la colaboración de las embajadas acreditadas en nuestro país, de las instituciones culturales, de las empresas y de personas particulares, que apoyaron desde un inicio la labor que generosamente habíamos emprendido con el firme propósito de llevar cultura a la población.

Así, una programación cultural total es nuestro actual objetivo, en la que, además de la música que ahora transmitimos veinticuatro horas diarias, los siete días de la semana en nuestra nueva presencia en el dial: 102.7 FM de Radio Filarmonía, el público oyente puede escuchar programas culturales preparados por emisoras internacionales, conferencias, charlas y entrevistas con personalidades de la historia, del arte, de la literatura y hasta de las ciencias, todo lo cual nos ha permitido constituir un archivo con más de ochenta mil horas de música y de programas culturales, el mismo que se encuentra a disposición de todos los oyentes pero, especialmente, de los estudiantes y profesores de la gran Universidad Ricardo Palma que, fiel a su patrono, el gran tradicionista, y al precepto de universalidad de la cultura, apoya a Radio Filarmonía desde hace once años.

De este modo, Radio Filarmonía se ha constituido en un referente cultural que, para nuestro orgullo, es objeto de estudio de parte de numerosos estudiantes de las facultades de Comunicación de diversas universidades e institutos superiores, a pedido expreso de sus profesores.

\section{El compromiso social del arte en la difusión de la cultura}

Para Radio Filarmonía es muy importante el compromiso con la difusión de la cultura. En tal sentido, desde hace algunos ańos, gracias a convenios con instituciones musicales superiores, nuestra emisora está llevando la música clásica en vivo a poblaciones alejadas de Lima, lo cual enriquece la vida espiritual de numerosos pobladores y permite, además, que los jóvenes músicos que forman parte de estas embajadas culturales se conecten directamentecon la realidad del país, demostrando con ello la perfecta relación que existe entre arte y sociedad.

Mucho es lo que Radio Filarmonía está aportando desde hace casi treinta años a la cultura del país. En octubre de este año, por ejemplo, desarrollamos el Segundo Concurso Nacional de Canto Lírico, cuyo objetivo es ayudar a jóvenes talentosos, peruanos y extranjeros residentes en el Perú, a desarrollar una carrera exitosa en el campo de la lírica. El primer concurso realizado el año pasado fue tan exitoso que concluyó con el viaje a Italia de los concursantes que obtuvieron el primer y segundo lugar, para recibir asesoramiento del gran tenor peruano Juan Diego Flórez en sus objetivos de postular y ser admitidos en las escuelas superiores de canto de Italia o Austria. 
Igualmente, las óperas que se presentan en el Metropolitan Opera House de los Estados Unidos han dejado de ser un espectáculo imposible para el público peruano pues Radio Filarmonía, gracias a un convenio con el mismo teatro de Nueva York, transmite por radio y en UVK Multicines, el mismo día y a la misma hora, las óperas que se están presentando en la ciudad americana.

Debo finalizar, pero antes quiero ofrecerles - con mi agradecimiento por la amable distinción- un extracto del célebre escritor francés Romain Rolland, para quien la música era el centro de su inspiración, de ese "palpitar de la vida eterna” que se hace presente como una oración. Escuchemos:

"La vida pasa. El cuerpo y el alma se desvanecen como las olas. Los años dejan su huella en la carne del árbol que envejece. El mundo entero de las formas se gasta y se renueva.

Tú sola, Música inmortal, no pasas. Tú eres el mar interior. Tú eres el alma profunda. En tus claras pupilas no se refleja el rostro melancólico de la vida. Como un rebaño de nubes se aleja de ti el cortejo de los dias ardientes, helados, febriles, fugitivos, que ahuyenta la inquietud. Sólo tú no pasas. Estás fuera del mundo. Constituyes por ti sola un mundo. Tú tienes tu sol, tus leyes, tu flujo y tu reflujo. Posees la paz de las estrellas que trazan en el campo de los espacios nocturnos su rasgo luminoso, arados de plata conducidos por la mano segura del labrador invisible.

Música, virgen madre que llevas en tus entrañas inmaculadas todas las pasiones; que encierras el bien y el mal en el lago de tus ojos del color de los juncos, del agua verde pálida que fluye de los glaciares, tú estás por encima del bien y del mal. Quien se refugia en ti vive al margen de los siglos; la sucesión de los días no será para él más que un dia infinito, y la muerte, que todo lo muerde, se romperá los dientes.

Música que acunaste mi alma dolorida, haciéndola firme, tranquila y alegre al inundarla de amor $y$ de bondad, quiero besar tu boca pura, esconder mi rostro entre tu cabellera de miel, apoyar mis pupilas abrasadas en la dulce palma de tu mano. Cuando cerramos los ojos y nos callamos veo la luz inefable de tus ojos, bebo la sonrisa de tus labios mudos, y acurrucado sobre tu corazón escucho el palpitar de la vida eterna.

Muchas gracias, nuevamente, señor rector. La distinción que esta querida universidad me ha concedido es también una música, una melodía que mi espíritu ha de escuchar siempre.

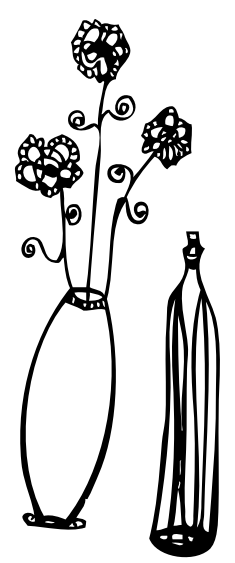

